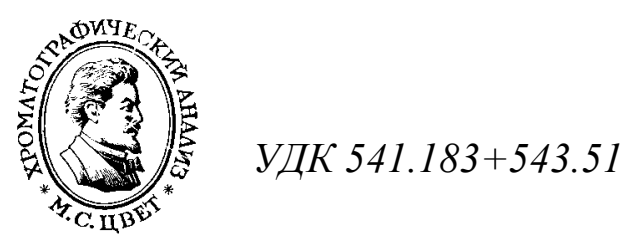

\title{
Скрининг продуктов трансформации 1,1-диметилгидразина на поверхности шунгита методом масс-спектрометрии МАЛДИ
}

\author{
Карнаева А.Е., Ярцев С.Д., Полунина И.А., Буряк А.К. \\ ФГБУН Институт физической химии и электрохимии им. А.Н. Фрумкина РАН, Москва \\ Поступила в редакцию 31.01.2017 г.
}

\begin{abstract}
Методом масс-спектрометрии с лазерной десорбцией/ионизацией (МАЛДИ) исследованы продукты окислительной трансформации 1,1-диметилгидразина. Показано, что из водных растворов на минеральном шунгите наиболее эффективно сорбируются относительно высокомолекулярные продукты трансформации 1,1-диметилгидразина. Сорбция наиболее токсичного продукта его трансформации - нитрозодиметиламина - происходит значительно быстрее из раствора в пиридине, чем из воды.
\end{abstract}

Ключевые слова: 1,1-диметилгидразин, шунгит, масс-спектрометрия МАЛдИ

\section{Screening of 1,1-dimethylhydrazine transformation products on shungite surface by MALDI mass spectrometry}

\author{
Karnaeva A.E., Iartsev S.D., Polunina I.A., Buryak A.K. \\ A.N. Frumkin Institute of Physical Chemistry and Electrochemistry, Russian Academy of Sciences, Moscow
}

1,1-dimethylhydrazine (unsymmetrical dimethyl hydrazine, UDMH) is a fuel component which is widely used in launch vehicles. When released into the environment UDMH undergoes oxidative transformation resulting in formation of a wide range of toxic products. In order to eliminate the negative impact of the propellant spills, the crash sites of the launch vehicles stages are treated with the material on the basis of shungite. An important task of environmental safety is the rapid detection of UDMH and its transformation products on the shungite surface. The application of MALDI mass spectrometry for screening of the UDMH transformation products is described in the present work, the adsorption of these compounds on the surface of shungite is studied. It is shown that the toxic components in real UDMH samples subjected to oxidation can be detected by means of MALDI mass-spectrometry. The study of the adsorption of these components from aqueous solutions showed that shungite sorbed relatively high molecular weight compounds at a higher rate, while for solutions in pyridine rapid sorption of low molecular weight compounds, including NDMA (the most toxic of the UDMH transformation products) was observed.

Keywords: 1,1-dimethylhydrazine, shungite, MALDI mass spectrometry

\section{Введение}

1,1-Диметилгидразин (несимметричный диметилгидразин, НДМГ) - компонент широко используемого ракетного топлива, физиологически активное токсичное соединение, которое легко и быстро окисляется на воздухе, образуя ряд предельных и непредельных азотоводородных и азотоуглеводородных соединений, некоторые из которых значительно превосходят его по токсичности [1-4]. В ходе ракетно- 
космической деятельности - при падении ступеней ракет-носителей, аварийных проливах - НДМГ попадает в окружающую среду, и на поверхностях различных материалов образуются сложные смеси продуктов его трансформации, качественный и количественный состав которых довольно сложно определить стандартными методами аналитической химии [4-7]. Экспериментально обнаружено, что при длительном хранении в закрытых емкостях НДМГ трансформируется с образованием низкои высокомолекулярных смолистых веществ, называемых продуктами осмоления, «осмолом» $[1,7]$.

Одним из способов обезвреживания мест проливов технологических жидкостей, содержащих НДМГ, является их обработка шунгитом. Обнаружено, что в результате взаимодействия шунгита с НДМГ концентрация токсина в воде в течение суток снижается в 5000 раз [7]. Уменьшение концентрации НДМГ авторы объясняли сорбцией и последующим разложением его молекул на поверхности шунгита - минерала, основу которого составляют диоксид кремния и аморфный углерод $[8,9]$. Особенностями этого минерального сырья являются дешевизна и большие природные запасы, химическая и каталитическая активность [8]. В зависимости от содержания углерода (от 5 до 99\%), различают пять разновидностей шунгитовых пород, из которых наиболее ярко выраженной адсорбционной способностью обладает шунгит третьей разновидности (шунгит-III), содержащий 20-40\% углерода [9].

Для исследования состава продуктов трансформации и осмоления НДМГ в различных средах и на межфазных границах применялись разнообразные методы масс-спектрометрии. Однако стандартные методы ионизации соединений при массспектральном анализе их смесей часто оказываются неэффективными, т.к. многие вещества не образуют стабильных молекулярных ионов в газовой фазе. Благодаря появлению методов масс-спектрометрии с «мягкой» лазерной ионизацией, не приводящих к разрушению сложных молекул и их значительной фрагментации, исследования биоактивных соединений и их поверхностных кластеров получили новый импульс в своем развитии. Метод МАЛДИ-МС (масс-спектрометрии с матричноактивированной лазерной десорбцией/ионизацией) используют для экспрессного обнаружения широкого круга органических соединений, т.к. он позволяет получать качественную информацию о составе сложной смеси без ее предварительного разделения [10-12]. В настоящей работе рассмотрены особенности применения массспектрометрии МАЛДИ для скрининга НДМГ и продуктов его трансформации на поверхности шунгита.

Цель работы - разработка подходов к экспрессному обнаружению продуктов трансформации НДМГ для оценки эффективности сорбции этих веществ на поверхности шунгита и детоксикации окружающей среды.

\section{Эксперимент}

В работе использовали водные растворы НДМГ, подвергшегося длительной окислительной трансформации в естественных условиях (так называемый «осмол»). В качестве адсорбента исследовали порошок минерального шунгита-III Зажогинского месторождения (Карелия, РФ) с размером частиц не более 20 мкм. Адсорбцию НДМГ и продуктов его трансформации на шунгите из водных и органических растворов проводили путем перемешивания суспензий на лабораторном шейкере.

Как исходные растворы НДМГ, так и его растворы после адсорбции на шунгите исследовали методом масс-спектрометрии МАЛДИ. Исследуемый раствор смешивали с раствором матрицы - 2,5-дигидроксибензойной кислоты (Bruker Daltonics, Германия), после чего каплю полученной смеси наносили на мишень из не-

Карнаева и др. / Сорбционные и хроматографические процессы. 2017. Т. 17. № 2 
ржавеющей стали. Образцы выдерживали при комнатной температуре до испарения растворителя. Анализ проводили на масс-спектрометре Bruker Daltonics Ultraflex II (Bruker, Германия), оснащенном времяпролетным масс-анализатором, азотным лазером (длина волны лазера - 337 нм, максимальная энергия - 110 мкДж, частота импульсов - 20 и 50 Гц, время между импульсами - 1 мкс). Детектировали положительные ионы в диапазоне $\mathrm{m} / \mathrm{z}$ 20-2000 Да. Сбор и обработку масс-спектров проводили с помощью программного обеспечения FlexControl 3.4 и FlexAnalysis 3.4.

Для приготовления растворов использовали деионизированную воду (Milli-Q, Millipore, США), а также пиридин (HPLC-grade, Sigma-Aldrich, США).

Препаративное разделение смеси продуктов трансформации НДМГ в воде проводили методом жидкостной хроматографии с УФ-детектированием, используя хроматограф Agilent 1200 с колонкой Zorbax SB C-18. В качестве элюента использовали смесь воды с ацетонитрилом (1:1).

\section{Обсуждение результатов}

При ионизации электронами в масс-спектрах высокомолекулярных соединений, как правило, отсутствуют молекулярные ионы и наблюдаются интенсивные осколочные ионы, что затрудняет идентификацию исходных соединений. Кроме того, при нагреве высокомолекулярные соединения, чаще всего, не десорбируются с поверхности, а разлагаются. Таким образом, получаемый масс-спектр является суммой масс-спектров десорбирующихся легких соединений и продуктов пиролиза высокомолекулярных соединений. В табл. 1 приведены соединения, идентифицированные методом термодесорбционной масс-спектрометрии, при анализе продуктов десорбции из образца шунгита, обработанного НДМГ. Помимо ионов, характерных для самого НДМГ (с отношением массы ионов к заряду $m / z 42,59,60$ ), и известных продуктов его трансформации удается зарегистрировать и крупные ионы азополиенов с массой до 300 Да [7, 11-12]. Состав смеси «продуктов осмоления» очень сложен, образующиеся соединения достаточно стабильны и могут накапливаться в объектах окружающей среды, представляя потенциальную угрозу человеку и природе [1-6].

Таблица 1.Продукты окислительной трансформации 1,1-диметилгидразина

\begin{tabular}{|c|c|c|}
\hline Название & Структурная формула & Мол. масса (Да) \\
\hline 1 & 2 & 3 \\
\hline N,N-Диметилформамид & & 73 \\
\hline Диметиламин & & 45 \\
\hline Триметиламин & & 59 \\
\hline Гуанидин & & 59 \\
\hline Диметилметиленгидразин & & 72 \\
\hline
\end{tabular}

Карнаева и др. / Сорбционные и хроматографические процессы. 2017. Т. 17. № 2 


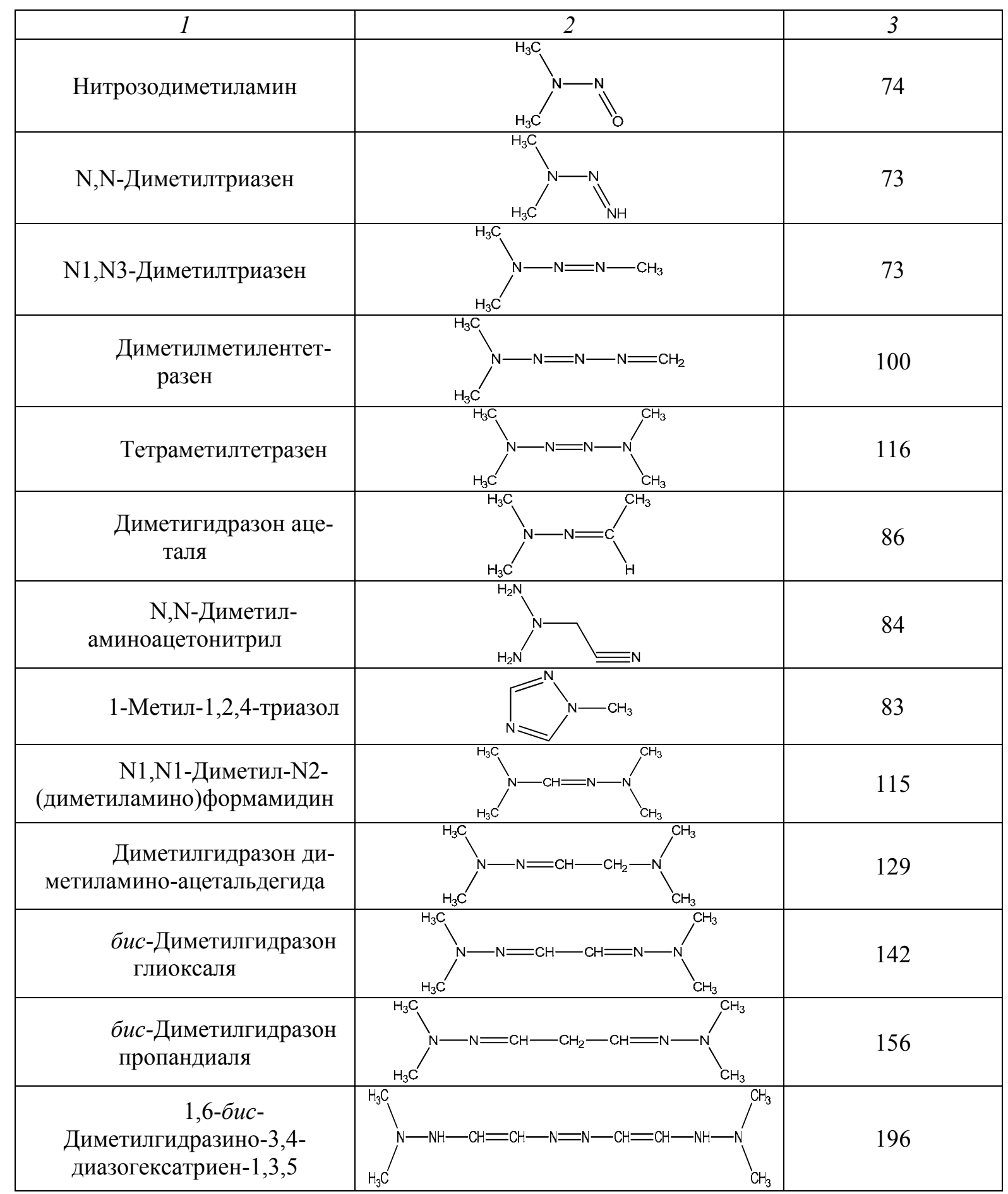

Для анализа высокомолекулярных соединений используют более мягкие методы ионизации, в частности, МАЛДИ. Методом масс-спектрометрии МАЛДИ в составе продуктов осмоления НДМГ (рис. 1а) удалось обнаружить вещества с молекулярной массой до 600 Да, относящиеся к азенам, азополиенам и другим продуктам вторичного окисления, конденсации, циклизации и олигомеризации азотоводородных и азотоуглеводородных соединений, подобные тем, что обнаруживали при исследовании продуктов трансформации на конструкционных материалах [11-12]. Сложный характер получающегося масс-спектра не позволяет провести полную идентификацию обнаруженных соединений. Однако можно утверждать, что в массспектре наблюдаются сигналы, соответствующие протонированным молекулам 
$[\mathrm{M}+\mathrm{H}]^{+}$НДМГ (m/z 61), протонированным молекулам используемой матрицы $(2,5-$ дигидроксибензойной кислоты с $m / z$ 155), триметиламина $(m / z$ 60), N1,N1-диметил$\mathrm{N} 2$-(диметиламино)формамидина $(\mathrm{m} / \mathrm{z} 58)$, нитрозодиметиламина $(\mathrm{m} / \mathrm{z} \quad 74)$, бисдиметилгидразона глиоксаля $(\mathrm{m} / \mathrm{z} 142)$ и 3,4 диазогексатриена- $1,3,5$ ( $\mathrm{m} / \mathrm{z} 199)$.

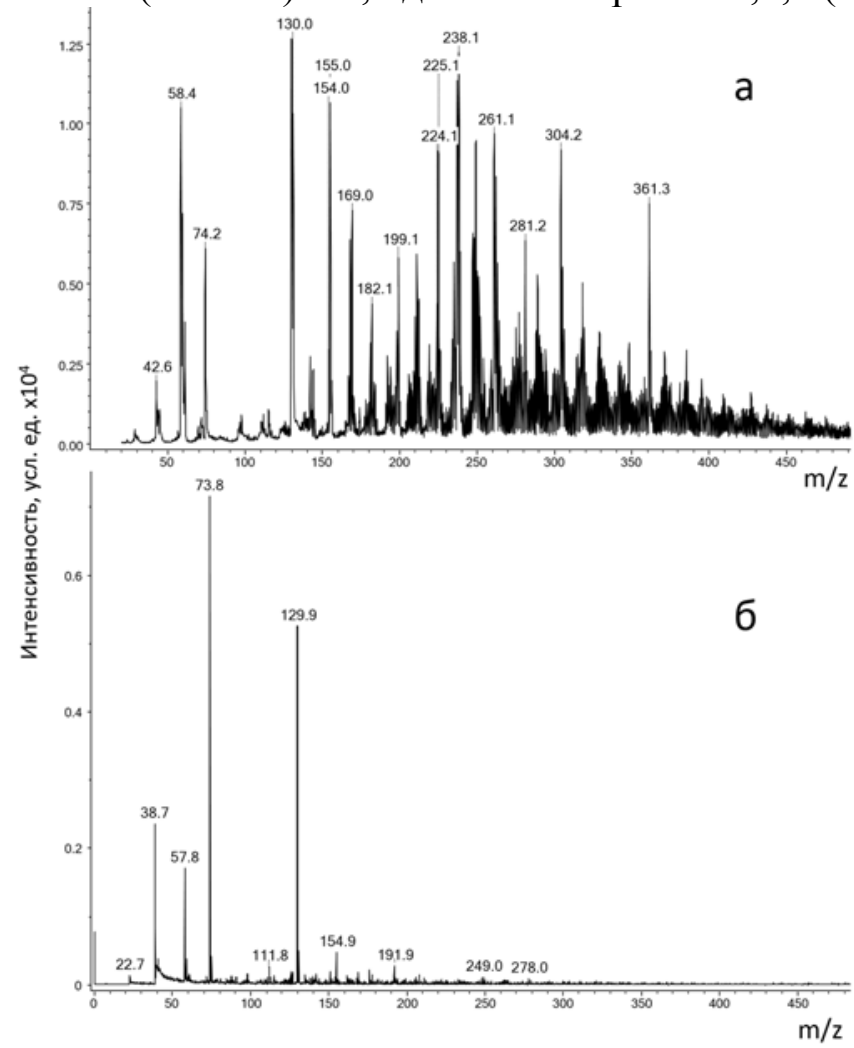

Рис. 1. Масс-спектр водного раствора продуктов окислительной трансформации НДМГ до сорбции $(a)$ и после сорбции на шунгите (б). Метод ионизации - МАЛДИ.

Хроматографическое препаративное разделение исследуемой смеси продуктов трансформации НДМГ методом ВЭЖХ позволило выделить две фракции, каждую из которых проанализировали методом МАЛДИ. Установлено, что первая фракция содержит практически чистый бис-диметилгидразон глиоксаля $(\mathrm{m} / \mathrm{z} 142)$, а вторая фракция - диметилгидразоно-диметиламино ацетальдегид ( $m / z$ 130), (рис. 2).

Сравнительное исследование методом МАЛДИ образцов «осмола», подготовленных с использованием матрицы и без нее позволило установить, что использование матрицы не влияет на процесс ионизации исследуемых веществ, а в некоторых случаях мешает ей. Однако после хроматографического отделения фракции с диметилгидразоно-диметиламино ацетальдегидом $(\mathrm{m} / \mathrm{z} 130)$ из смеси продуктов «осмола» использование метода МАЛДИ без матрицы оказалось невозможным. По-видимому, диметилгидразоно-диметиламино ацетальдегид способен выполнять роль матрицы.

На рис. 16 приведен масс-спектр водного раствора «осмола» НДМГ, взаимодействовавшего с шунгитом в течение 1 ч. Эффективность сорбции оценивали исходя из отношения интенсивностей сигнала с $m / z 74$, соответствующего самому токсичному из продуктов трансформации НДМГ - нитрозодиметиламину - к интенсивности сигнала сравнительно менее токсичного диметилгидразоно-диметиламино ацетальдегида с $m / z$ 130. По сравнению с масс-спектром исходного раствора «осмола» (рис. 1а) значительно снизилась интенсивность пиков относительно высокомолекулярных соединений с $\mathrm{m} / z$ более 160 . Можно заключить, что эти компоненты 
сорбируются на шунгите количественно. Отношение интенсивностей пиков с $\mathrm{m} / \mathrm{z} 74$ и 130 увеличилось, т.к. пик с $\mathrm{m} / z$ 74, соответствующий нитрозодиметиламину, стал относительно более интенсивным. По-видимому, нитрозодиметиламин сорбируется из водных растворов «осмола» НДМГ в меньшей степени, чем другие компоненты. Подобная картина не меняется со временем (исследовалась динамика сорбции в течение 2 ч).

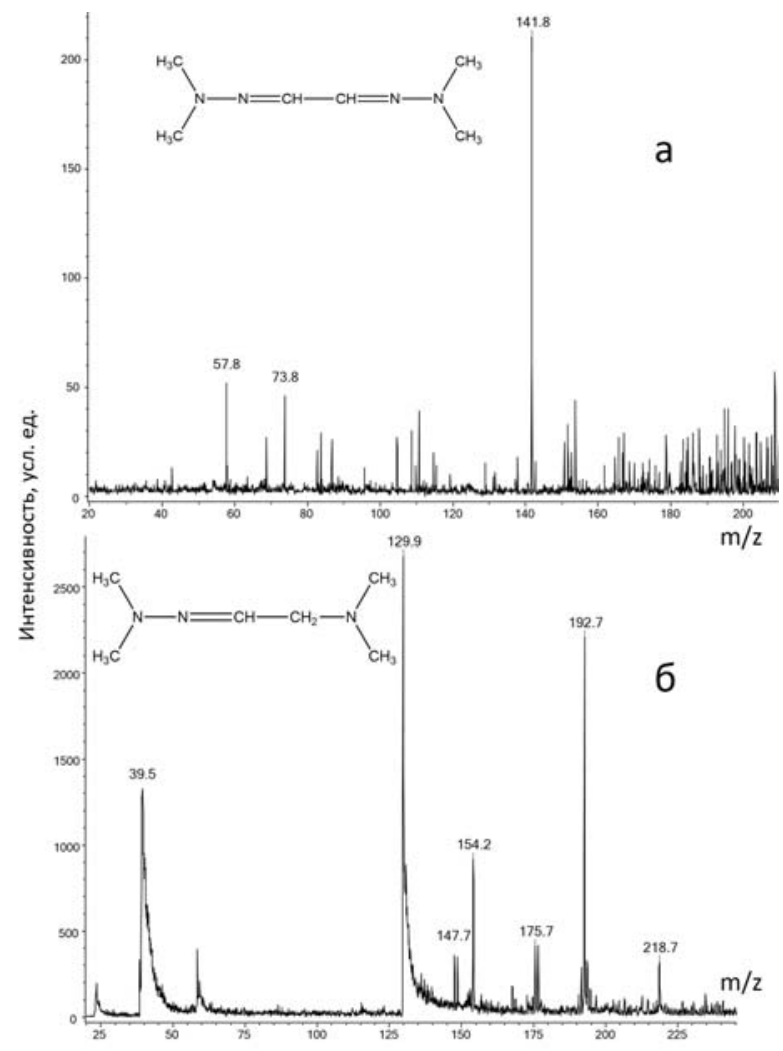

Рис. 2. Масс-спектры, полученные при исследовании препаративно выделенных фракций водного раствора продуктов окислительной трансформации НДМГ: $a$ - бис-диметилгидразон глиоксаля ( $\mathrm{m} / \mathrm{z} 141.8), \sigma$ - диметилгидразоно-диметиламино ацетальдегид ( $m / z$ 129.9)

При растворении «осмола» НДМГ в пиридине наблюдается обратная ситуация. На рис. 3 приведены масс-спектры исходного раствора «осмола» в пиридине $(a)$ и того же раствора через 1 ч сорбции на шунгите (б). Сравнивая масс-спектры растворов «осмола» в воде и пиридине (рис. 1а и рис. 3а), можно заметить, что раствор в пиридине содержит значительно меньшее количество соединений. По-видимому, это вызвано более слабой сольватацией продуктов трансформации НДМГ молекулами пиридина, по сравнению с молекулами воды. После сорбции «осмола» на шунгите относительная интенсивность пика нитрозодиметиламина $(\mathrm{m} / z$ 74) значительно уменьшается, т.е. из растворов в пиридине нитрозодиметиламин сорбируется в большей степени, чем другие компоненты «осмола».

Таким образом, методом масс-спектрометрии МАЛДИ обнаружено, что относительно высокомолекулярные соединения с большей скоростью сорбируются на шунгите из водных растворов «осмола», в то время как из растворов в пиридине наблюдается быстрая сорбция низкомолекулярных соединений, в том числе нитрозодиметиламина (самого токсичного из продуктов трансформации НДМГ), т.е. использование пиридина для сорбционной очистки «осмола» от токсичного нитрозодиметиламина, более эффективно, чем использование воды. 


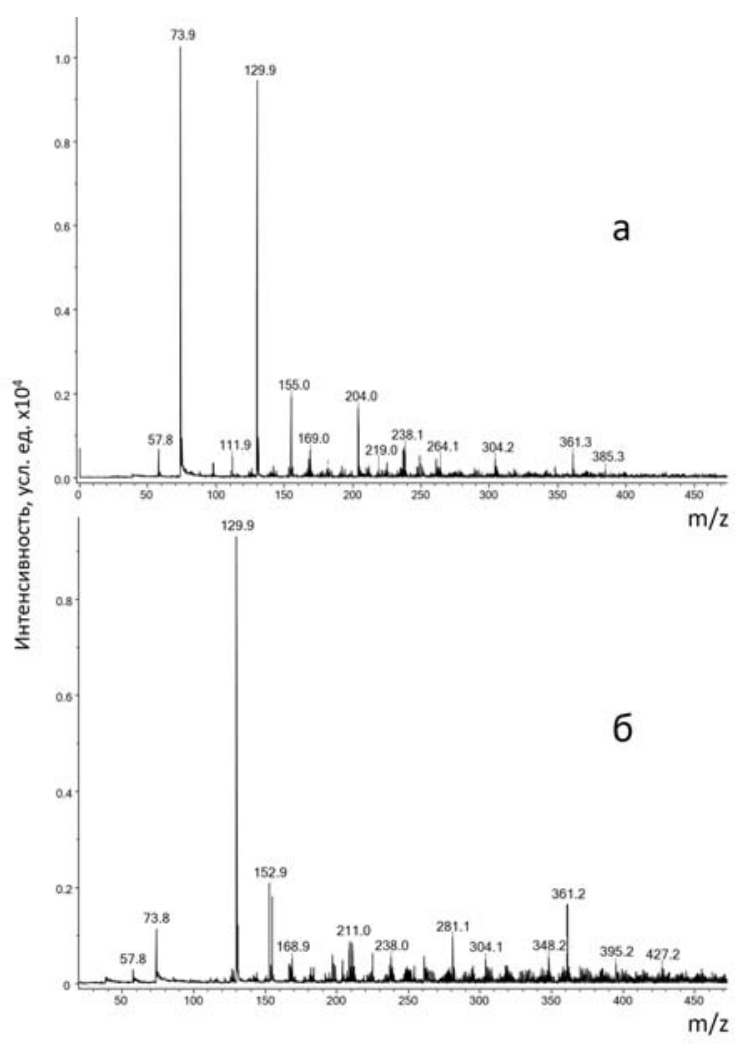

Рис. 3. Масс-спектр раствора продуктов окислительной трансформации НДМГ в пиридине до сорбции $(a)$ и после сорбции на шунгите в течение 1 ч (б). Метод ионизации - МАЛДИ.

\section{Заключение}

Методом масс-спектрометрии с лазерной десорбцией/ионизацией (МАЛДИ) исследованы продукты окислительной трансформации 1,1-диметилгидразина («осмола») в воде и пиридине до и после контакта растворов с минеральным шунгитом. Показано, что метод МАЛДИ-МС позволяет проводить экспрессное обнаружение продуктов трансформации НДМГ в исследуемых растворах, что делает его ценным инструментом для изучения процессов окисления и сорбции. Наиболее эффективно на шунгите из водных растворов сорбируются относительно высокомолекулярные продукты трансформации НДМГ. Обнаружено, что нитрозодиметиламин - наиболее токсичный продукт его трансформации - более эффективно сорбируется на шунгите из раствора в пиридине, чем из водного раствора.

\section{Работа выполнена при финансовой поддержке РФФИ}

(гранты 15-08-08006 и 17-08-00315).

\section{Список литературы}

1. Буряк А.К., Сердюк Т.М. // Усnехи химии. 2013. Т. 82. С.369-392.

2. Экологический мониторинг ракетнокосмической деятельности. Принципы и методы / Под ред. Н.С. Касимова, О.А. Шпигуна. М.: Рестарт. 2011. 472 с.
3. Schmidt E. Hydrazine and its derivatives. N.Y.: Wiley and Sons. 1984. 340 p.

4. Костюковский Я.Л., Меламед Д.Б. // Успехи химии. 1988. Т. 57. № 4. С. 625-655. 
5. Ушакова В.Г., Шпигун О.А., Старыгин О.И. // Ползуновский вестник. 2004. № 4. С. 177-184.

6. Rodin I.A., Anan'eva I.A., Smolenkov A.D., Shpigun O.A. // J. Analyt. Chem. 2010. Vol. 65. No 13. pp. 1405-1410.

7. Голуб С.Л., Ульянов А.В., Буряк А.К., Луговская И.Г. и др. // Сорбиионные и хроматографические проиессы. 2006. Т.6. № 5. C.748-763.

8. Шунгиты - новое углеродистое сырье / Под ред. В.А. Соколова, Ю.К. Калинина, Е.Ф. Дюккиева. Петрозаводск: Карелия, 1984, 182 c.

\section{References}

1. Buryak A.K., Serdyuk T.M., Russ. Chem. Rev., 2013, Vol. 82, No. 4, pp. 369-392.

2. Ekologicheskii monitoring raketnokosmicheskoi deyatelnosti. Princzipi and metodi / Pod red. N.C Kasimova, O.A.Shpiguna. M., Restart, 2011, 472 p.

3. Schmidt E. Hydrazine and its derivatives. N.Y.: Wiley and Sons, 1984, $340 \mathrm{p}$.

4. Kostyukovskii Ya.L., Melamed D.B., Russ. Chem. Rev., 1988, Vol. 57. No 4, pp. 625-655.

5. Ushakova V.G., Shpigun O.A., Starigin O.I., Polzunovskii vestnik, 2004, No4, pp. 177184.

6. Rodin I.A., Anan'eva I.A., Smolenkov A.D., Shpigun O.A., J. Analyt. Chem., 2010, Vol. 65, No 13, pp. 1405-1410.

7. Golub S.L., Ulyanov A.V., Buryak A.K., Lugovskaja I.G. et al., Sorbtsionnye i khroma-

Ярцев Степан Дмитриевич - аспирант Институт физической химии и электрохимии им. А.Н.Фрумкина РАН (ИФХЭ РАН), Москва, (495) 955-46-85

Карнаева Анастасия Евгеньевна - стажер, ИФХЭ РАН, Москва, 495) 955-46-85

Полунина Ирина Александровна - к.х.н., доцент, ведущий научный сотрудник, ИФХЭ РАН, Москва, (495) 955-46-90

Буряк Алексей Константинович - д.х.н., профессор, заведующий лабораторией, ИФХЭ РАН, Москва, (495) 955-46-85,
9. Полунина И.А., Высоцкий В.В., Сенчихин И.Н., Гончарова И.С. и др. // Коллоид.журн. 2017. Т.79. № 2. С.192-197.

10. Полунин К.Е., Гончарова И.С., Ульянов А.В., Полунина И.А. и др. // Коллоид. журн. 2017. Т. 79. № 2. С. 198-205.

11. Ярцев С.Д., Пыцкий И.С., Карнаева А.Е., Буряк А.К.// Химическая физика. 2017. Т. 36. № 8 (в печати)

12. Ярцев С.Д., Пыцкий И.С., Зенкевич И.Г., Буряк А.К. // Журн. аналитической химии. 2017. Т. 72. № 6 (в печати)

tograficheskie protsessy,2006, Vol. 6, No 5, pp. 748-763.

8. Shungity - novoe uglerodistoe syr'e / Ed. V.A. Sokolov, Ju.K. Kalinin, E.F. Djukkiev. Petrozavodsk: Karelija, 1984, 182 p.

9. Polunina I.A., Visotskii V.V., Senchikhin I.N., Polunin K. E. et al., Colloid J., 2017, Vol. 79, No 2, pp. 244-249.

10.Polunin K. E Goncharova I.S., Ulyanov A.V., Polunina I.A. et al., Colloid J., 2017, Vol. 79, No 2, pp. 250-257.

11.Iartsev S.D., Pytskii I.S., Karnaeva A.E., Buryak A.K, Rus. J. Phys. Chem.B, 2017, Vol. 36, No 8 (in print)

12.Iartsev S.D., Pytskii I.S., Zenkevich I.G., Buryak A.K , J. Analyt. Chem., 2017, Vol. 72, No 6,(in print)

Iartsev Stepan D. - Ph.D. student, A.N.Frumkin Institute of Physical Chemistry and Electrochemistry, Russian Academy of Sciences (IPCE RAS), Moscow yartsew1@yandex.ru

Karnaeva Anastasiya E. - post graduate student, IPCE RAS, Moscow, akburyak@mail.ru

Polunina Irina A. - Ph.D. (chemistry), associate prof., senior researcher, IPCE RAS, Moscow, polunina@phyche.ac.ru

Buryak Alexei K. - prof., Dr. Sci. (chemistry), head of laboratory, IPCE RAS, Moscow, akburyak@mail.ru 